\title{
Thermally Stable Forms of Pure Polyaniline Catalyzed by an Acid-Exchanged Montmorillonite Clay Called Maghnite- $\mathrm{H}^{+}$as an Effective Catalyst
}

\author{
Rahmouni Abdelkader, Harrane Amine, and Belbachir Mohammed \\ Département de Chimie, Faculté des Sciences, Université d'Oran, BP 1524, El M'nouar, 31000 Oran, Algeria \\ Correspondence should be addressed to Rahmouni Abdelkader, ramaek51@yahoo.fr \\ Received 7 April 2012; Accepted 2 June 2012 \\ Academic Editor: Murali Mohan Yallapu
}

Copyright (c) 2012 Rahmouni Abdelkader et al. This is an open access article distributed under the Creative Commons Attribution License, which permits unrestricted use, distribution, and reproduction in any medium, provided the original work is properly cited.

Polyaniline salt form (PANI-ES) was synthesized by oxidative polymerization of aniline using potassium persulfate as an oxidant and an acid-exchanged montmorillonite clay called Maghnite- $\mathrm{H}^{+}$as an effective catalyst. The clay, which was used as a catalyst, was supplied by a local company known as ENOF Maghnia (Western Algeria). The chemical stability of PANI has been investigated by thermogravimetry and differential scanning calorimetry, that a good thermal stability of PANI could be improved by combining PANI with montmorillonite. TGA results illustrated that there were two major stages for weight loss of the ES-form PANI powder sample. The different forms of PANI were characterized by infrared spectroscopy, thermal analysis, and H-NMR spectroscopy and conductivity measurements.

\section{Introduction}

As a new organic metal and electrically conductive material, polyaniline continues to attract extensive attention from scientists and engineers although its chemical synthesis was reported almost one century ago [1]. Polyaniline is environmentally stable and inert. It has a wide range of potential technological applications including storage batteries, electrochromic devices, light emitting diodes, corrosion inhibitors, and a variety of sensors including chemical [2]. Polyaniline has been combined with inorganic materials such as montmorillonite [3]. In recent years layered silicates or clays have found their way for being used as fillers for polymers to increase many properties including tensile strength, modulus, barrier, thermal stability, and ignition temperature [4]. The polymerization of polyaniline was induced in heterogeneous phase by Maghnite- $\mathrm{H}^{+}$under suitable conditions. Maghnite- $\mathrm{H}^{+}$is a montmorillonite sheet silicate clay exchanged with protons [5]. Researchers have demonstrated that the introduction of only a small amount of clay into the polymer structure of polyaniline can lead to a significant enhancement of its properties [6]. Therefore, the aim of this paper is to improve the thermal stability of polyaniline through the synthesis with layered materials. The thermogravimetric analysis and differential scanning calorimetry demonstrated the improved thermal stability of the intercalated nanocomposites relative to the pure polyaniline due to the incorporated $\mathrm{Na}^{+}$-montmorillonite. This paper reports the properties of a series of PANI-Mag composites which were prepared by emulsion polymerization of aniline in the presence of a Maghnite substrate. The proposed process for the polymerization is show in Scheme 1. Based on the TGA and DSC results, thermal aging experiments were designed to study the thermal reactions of PANI-ES, PANI-EB, and PANI-HCL by infrared spectroscopy, UV spectroscopy, and $\mathrm{H}^{1}$-NMR spectroscopy.

\section{Experimental}

2.1. Materials. Aniline $99 \%$, potassium persulphate $98 \%$ (Aldrich), hydrochloric acid (35\%-38\%), MMT clay were obtained from ENOF Maghnia (Algeria). The MMT-H ${ }^{+}$ 

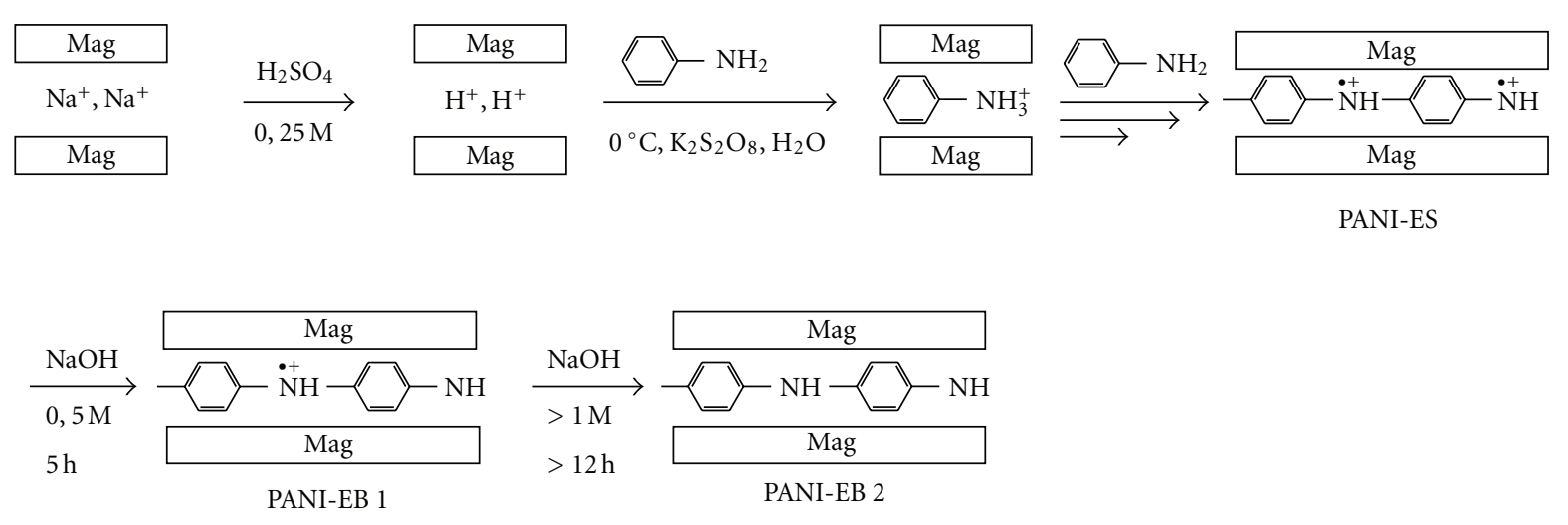

Scheme 1: Proposed process for soluble polyaniline catalysed Mag- $\mathrm{H}^{+}$.

$\left(\mathrm{Mag}-\mathrm{H}^{+}\right)$was prepared as described by Belbachir and Bensaoula [7], and water $(\mathrm{PH}<7)$ was used to synthesis emeraldine salt $\left(\mathrm{PANI}-\mathrm{Mag}-\mathrm{H}^{+}\right.$) by emulsion polymerization. Some of the emeraldine base (PANI-EB), nonconducting form of polyaniline, was prepared by de-protonating PANIES in $\mathrm{NaOH}$ solution $(0.5 \mathrm{M})$. A doping EB was carried out in aqueous medium of hydrochloric acid (HCL) $[8,9]$.

\subsection{Measurements}

2.2.1. Infrared Spectroscopy. Fourier transform infrared spectroscopy (FTIR) spectra were obtained between 900 and $4000 \mathrm{~cm}^{-1}$ on an ATI Mattson FTIR no. 9501165 . Ten scans were averaged at a resolution of $4 \mathrm{~cm}^{-1}$ for the solid tested samples of modified and unmodified montmorillonite prepared as $\mathrm{KBr}$ pellets (ca. $3 \%$ by mass in $\mathrm{KBr}$ ).

2.2.2. ${ }^{1} H$-NMR Spectroscopy. nuclear magnetic resonance (NMR) measurements were carried out on a $300 \mathrm{MHz}$ Bruker NMR spectrometer equipped with a probe BB05 mm, in $\mathrm{CDCl}_{3}$. tetramethylsilane (TMS) was used as the internal standard in these cases.

2.2.3. Conductivity. Conductivity measurements were carried out using a Lucas Lab resistivity equipment with four probes in line. The samples were dried in vacuum during 24 hours, and pellets of $13 \mathrm{~mm}$ diameter were prepared using FTIR mold by applying a pressure of $10 \mathrm{Tn} / \mathrm{cm}^{2}$.

2.2.4. Differential Scanning Calorimetry. DSC measurements were carried out on a TA instrument, according to the following program: the specimens were first heated from ambient temperature to $250^{\circ} \mathrm{C}$ at $10^{\circ} \mathrm{C} / \mathrm{min}$, maintained at this temperature during 5 minutes, then cooled to $25^{\circ} \mathrm{C}$ at $20^{\circ} \mathrm{C} / \mathrm{min}$.

2.2.5. Thermogravimetric Analysis (TGA). The tests were performed on a TA instrument (TGA Q500) by heating the samples from 20 to $550^{\circ} \mathrm{C}$ at $20^{\circ} \mathrm{C} / \mathrm{min}$, with DTG thermograms giving the variations of the weight loss derivative as a function of temperature.
2.3. Preparation of Maghnite- $\mathrm{H}^{+}$. Maghnite- $\mathrm{H}^{+}$was prepared according to the process reported in our previous study [10]. Raw Maghnite (20 g) was crushed for $20 \mathrm{mn}$ using a prolabo ceramic balls grinder. It was then dried for $2 \mathrm{~h}$ at $105^{\circ} \mathrm{C}$. The Maghnite was placed in an Erlenmeyer flask together with $500 \mathrm{~mL}$ of distilled water. The Maghnite/water mixture was stirred using a magnetic stirrer and combined with $0.25 \mathrm{M}$ sulfuric acid solution, until neutralization was achieved over 2 days at room temperature, the mineral was then washed with distilled water to become sulfate-free and then dried at $105^{\circ} \mathrm{C}$.

2.4. Synthesis of Different Forms of Polyaniline. Polyaniline salt (PANI-ES) was synthesized by the chemical oxidation of aniline with potassium persulfate $\left(\mathrm{K}_{2} \mathrm{~S}_{2} \mathrm{O}_{8}\right)$, water, and montmorillonite $\left(\mathrm{Mag}-\mathrm{H}^{+}\right)$and the mixture was precooled to below $0^{\circ} \mathrm{C}$ in an ice bath.

$5.1 \mathrm{~mL}$ of $(0.055 \mathrm{~mol})$ aniline was added to $6 \%$ of $(0.356 \mathrm{~g}) \mathrm{Mag}-\mathrm{H}^{+}$clay catalyst layered. The reaction was stirring for $30 \mathrm{mn}$ at $0^{\circ} \mathrm{C}$, after this time $3 \mathrm{~g}$ of $(0.013 \mathrm{~mol})$ oxidant was added slowly during $10 \mathrm{mn}$, after this we added drop by drop $15 \mathrm{~mL}$ of water. The reaction was continued for $1 \mathrm{~h}$ and $30 \mathrm{~min}$ in the optimal condition $\left(0^{\circ} \mathrm{C}\right)$.

The precipitate product was filtered and washed with distilled water as far as neutralization, because this product contained traces of initiator, oligomer, and monomer. In the end, we obtained black solid which is composed of polymerMag. However, the Mag- $\mathrm{H}^{+}$is separated by filtration because it's insoluble in the solvents in which the polymer is soluble.

Eventually, the resultit's black solution (polymer-solvent), after evaporation result a black powderit's (PANI-ES), washed several times with water and methanol, where dried at $60^{\circ} \mathrm{C}$ for $48 \mathrm{~h}$ for characterization.

The polyaniline base (PANI-EB) is obtained by deal treatment of polyaniline salt (PANI-ES) with a solution of dilute $\mathrm{NaOH}(0.5 \mathrm{M})$. Then, the prepared ES-form PANI was converted to EB-form PANI by stirring with $200 \mathrm{~mL}$ of $0.5 \mathrm{M} \mathrm{NaOH}$ dilute solution at room temperature for 5 to 10 hours. At the end of the stirring, the PANI-EB was filtered, washed with water and methanol several times, and dried under vacuum at $60^{\circ} \mathrm{C}$ for 48 hours by characterization. 
TABLE 1: The vibration frequencies of PANI-ES and PANI-EB.

\begin{tabular}{lcc}
\hline PANI-EB & PANI-ES & Vibration frequencies $\mathrm{cm}^{-1}$ \\
\hline 3631 & 3288 & Assignment \\
1555 & 1557 & Asymmetric N-H stretching \\
1295 & 1293 & Aromatic C-C stretching \\
1174 & 1168 & C-N stretching of secondary aromatic amine \\
849 & 838 & C-H in plane bending 1,4 disubstituted benzene \\
\hline
\end{tabular}

Finally, $1.53 \mathrm{~g}$ of the dark black EB-form PANI powder was obtained (84.14\% yield). A doping EB was carried out in aqueous medium of hydrochloric acid (1 M). Approximately $1.5 \mathrm{~g}$ of fine powder of polyaniline base was suspended in $200 \mathrm{~mL}$ of appropriate acid solution. After stirring at room temperature for $5 \mathrm{~h}$, the black polymer salt was collected by filtration followed by drying under dynamic vacuum for $48 \mathrm{~h}$ at $60^{\circ} \mathrm{C}$.

\section{Results and Discussion}

3.1. FTIR Spectral Analysis. The FTIR spectra of the PANIES and PANI-EB under the same conditions were shown in Figures 1 and 2. The FTIR spectroscopy evidence the formation of polyaniline structure containing 1,4-paradisubstituted linear chain. The vibration frequencies of the major infrared bands and their assignment for polyaniline PANI-ES and PANI-EB are summarized in Table 1.

3.2. ${ }^{1} \mathrm{H}$-NMR Spectral Analysis. The ${ }^{1} \mathrm{H}-\mathrm{NMR}$ spectra of the PANI-ES and PANI-EB polymers exhibit strongest sharp peak centered at $7 \mathrm{ppm}$ and $7.8 \mathrm{ppm}$ due to protons on phenylene and disubstituted phenylene units, the weak peak at $4.81 \mathrm{ppm}$ and medium broad peak at $6.22 \mathrm{ppm}$ due to ($\mathrm{NH}-$ and $-\mathrm{NH}_{2}$ ) end group, respectively. Other broad peaks centered at $1.78 \mathrm{ppm}$ and $8 \mathrm{ppm}$ may be due to the water protons bonded by $\left(-\mathrm{NH}-\right.$ and $\left.-\mathrm{NH}_{2}\right)$ groups and $\left(\mathrm{H}-\mathrm{N}^{+}\right)$, respectively, as shown in Figures 3 and 4 [11].

\subsection{Thermal Analysis}

(A) Thermal Analysis of Maghnite- $\mathrm{Na}^{+}$. The thermal characterizations of the composites include thermogravimetric analysis (TGA) and differential scanning calorimetry (DSC). Weight losses (\%) versus temperature $\left({ }^{\circ} \mathrm{C}\right)$ curves for pure Maghnite- $\mathrm{Na}^{+}$are shown in Figures 5 and 6. In Figure 5, the TGA of pure Maghnite- $\mathrm{Na}^{+}$shows two stages of weight loss. The first weight loss in $\mathrm{Na}^{+}$-Mag below $100^{\circ} \mathrm{C}$ is a result of the release of free water. The second weight loss around $600^{\circ} \mathrm{C}$ is associated with the dehydroxylation of silicate structure $[12,13]$. The total weight loss is only $13.94 \%$ up to $800^{\circ} \mathrm{C}$. As can be expected, Maghnite- $\mathrm{Na}^{+}$shows a high thermal stability.

(B) Thermal Analysis of DifferentForms of PANI. The TGA thermogram of the polyaniline (PANI-ES) at a heating rate of

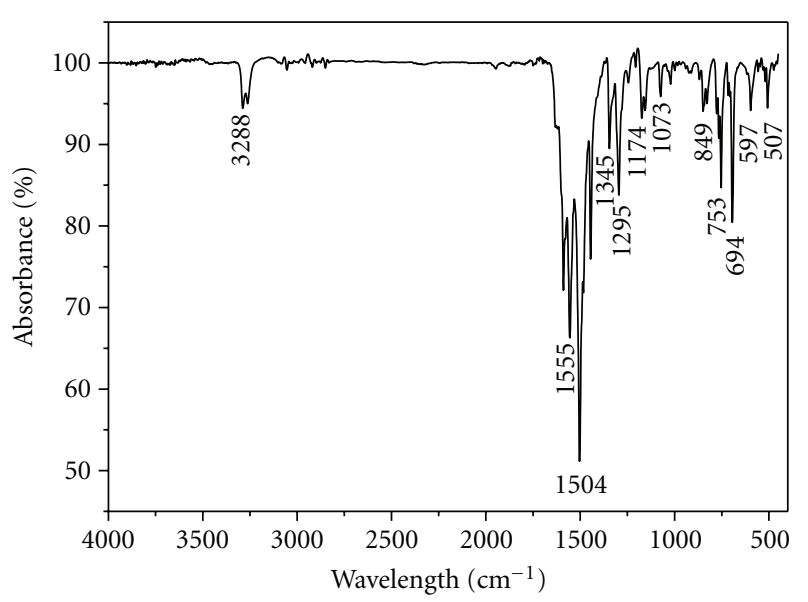

FIGURE 1: FT-IR spectra of the reduced polymer (PANI-EB) prepared at $25^{\circ} \mathrm{C}$.

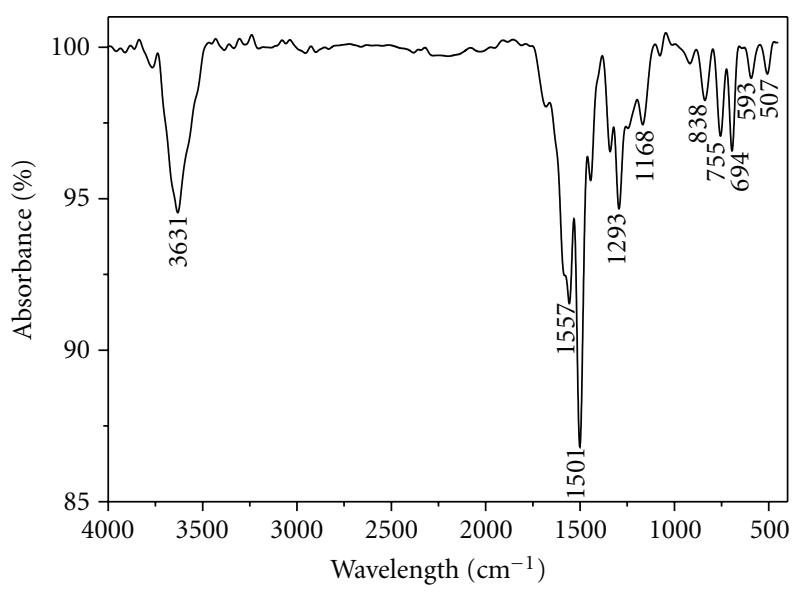

FIGURE 2: FT-IR spectra of the polymer (PANI-ES) obtained by the persulfate oxidation method (emeraldine black) at $0{ }^{\circ} \mathrm{C}$.

$10^{\circ} \mathrm{C} / \mathrm{min}$ in nitrogen is shown in Figure 7. It can be found that at the temperature range of $187-600^{\circ} \mathrm{C}$ the weight loss amounted to $61,17 \%$, which can be reasonably attributed to the weight loss of the polymerized polyaniline (PANI-ES) and to thermal decomposition of the polyaniline chains.

Polyaniline is known to be a hygroscopic polymer [14]. Some authors [15] assigned the endothermic effect registered by DSC in the range from ambient temperature up to approximately $120^{\circ} \mathrm{C}$ to the evaporation of water. 


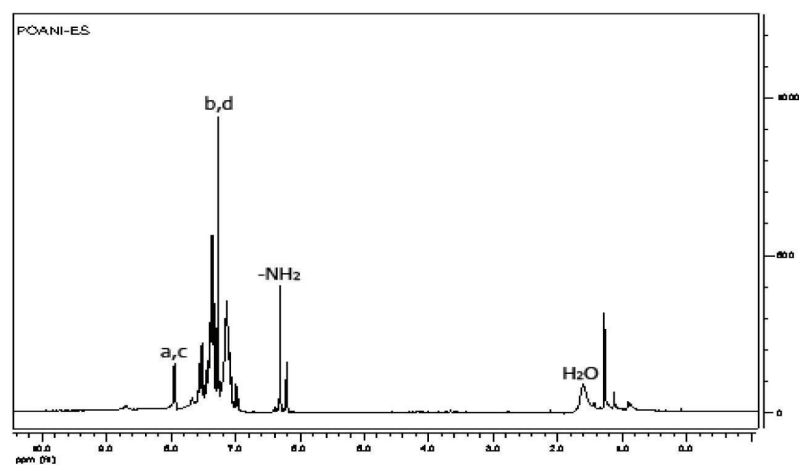

FIGURe 3: ${ }^{1} \mathrm{H}$ NMR spectrum $\left(300 \mathrm{MHz}, \mathrm{CDCl}_{3}\right.$, tetramethylsilane (TMS) were used as the internal standard) of polyaniline (PANI-ES) obtained by the polymerization of aniline with Mag- $\mathrm{H}^{+}$initiator system in $\mathrm{CDCl}_{3}$ at $0^{\circ} \mathrm{C}$.

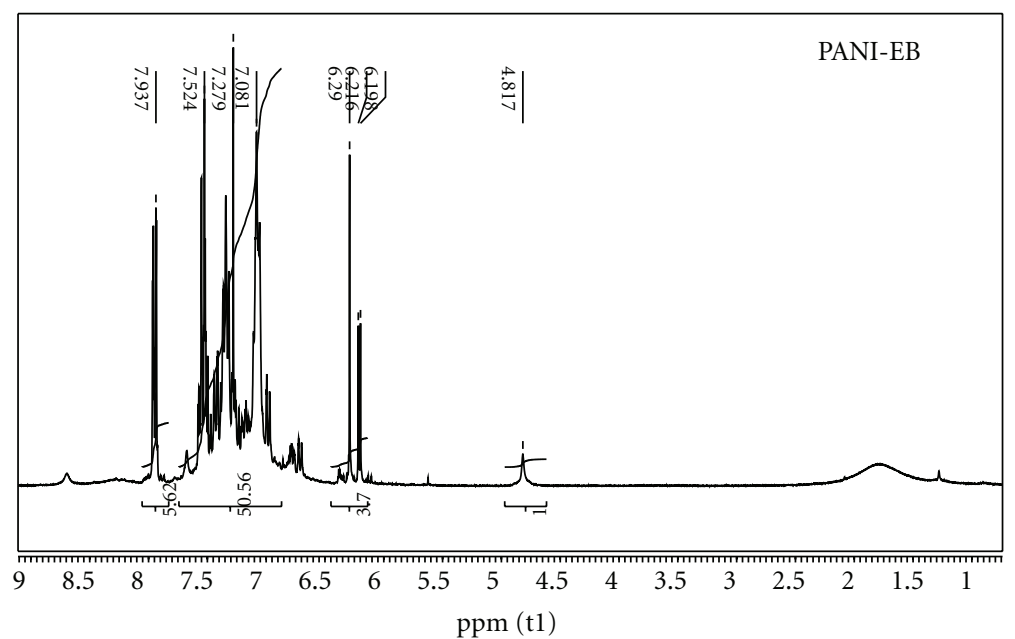

Figure 4: ${ }^{1} \mathrm{H}$ NMR spectrum (300 MHz, $\mathrm{CDCl}_{3}$, tetramethylsilane (TMS) were used as the internal standard) of polyaniline (PANI-EB) obtained by the polymerization of aniline with Mag- $\mathrm{H}^{+}$initiator system in $\mathrm{CDCl}_{3}$ at $25^{\circ} \mathrm{C}$.

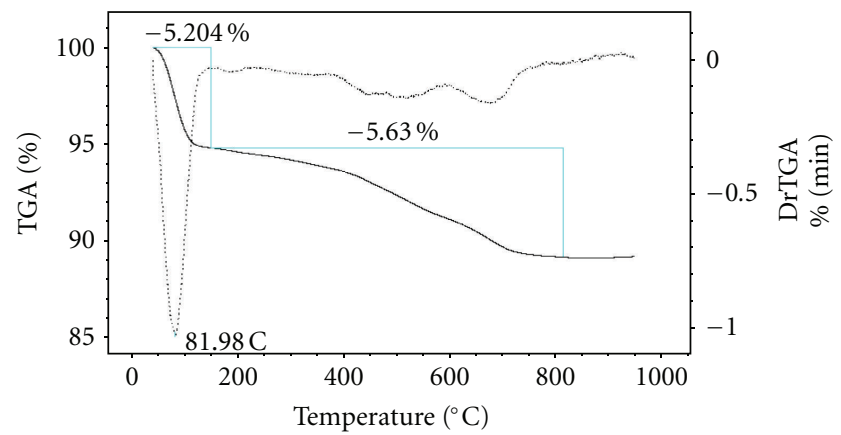

FIgURE 5: TGA curves of a Maghnite- $\mathrm{Na}^{+}$obtained in nitrogen atmosphere at heating rate of $10^{\circ} \mathrm{C} / \mathrm{min}$.

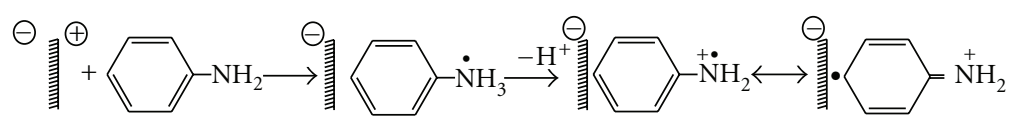

Scheme 2 


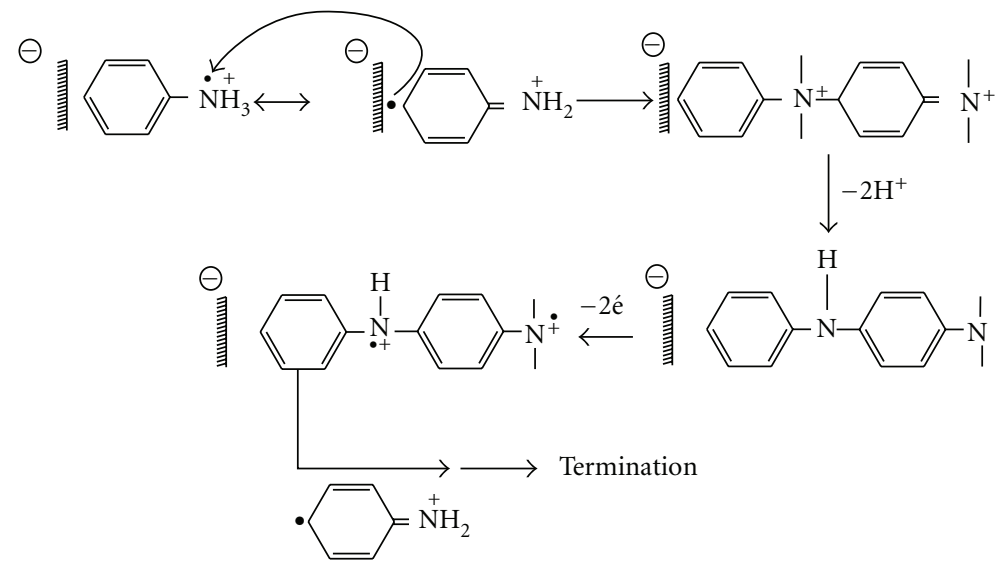

SCHEMe 3

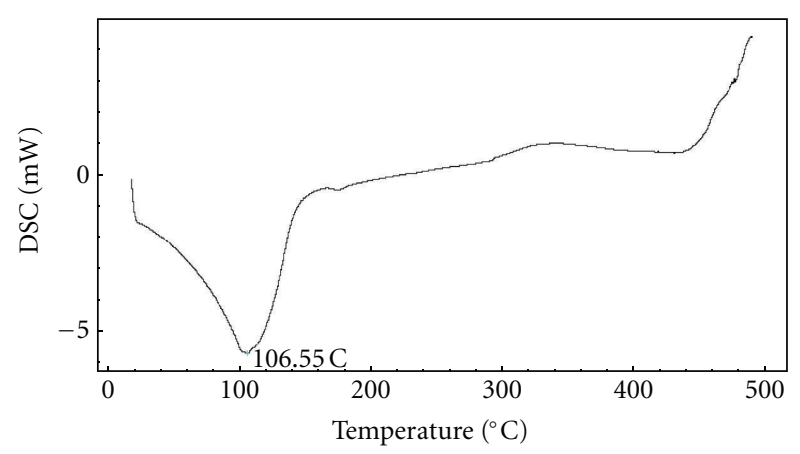

Figure 6: DSC Curve of Maghnite- $\mathrm{Na}^{+}$obtained in nitrogen atmosphere at heating rate of $10^{\circ} \mathrm{C} / \mathrm{min}$.

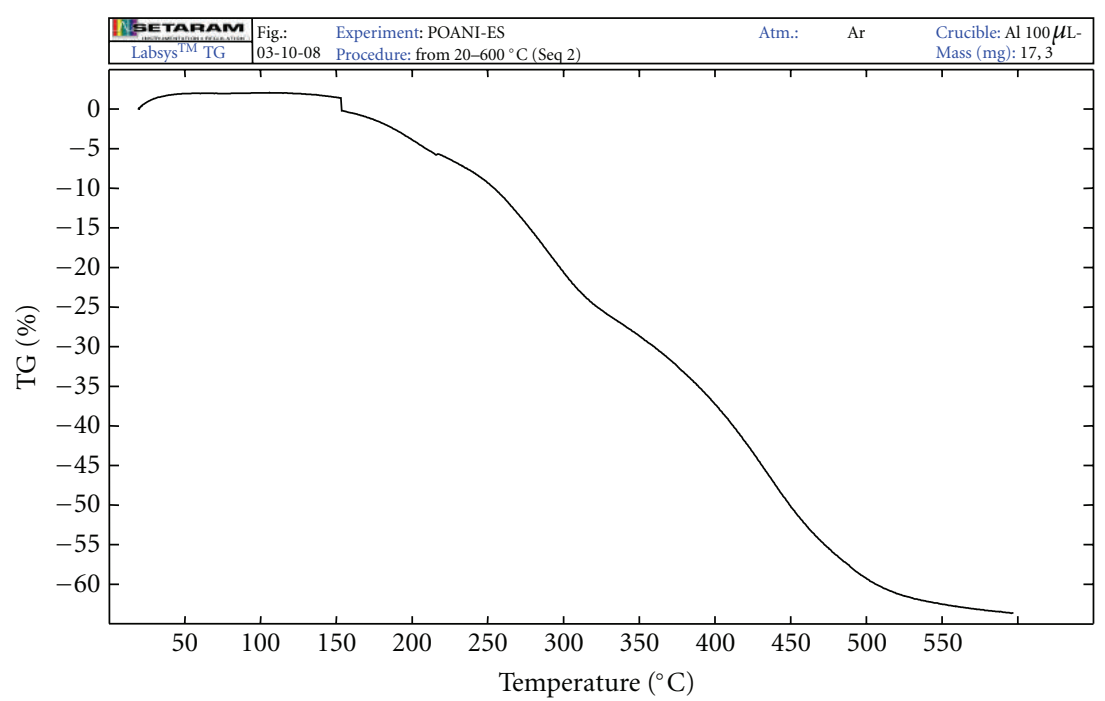

FIGURE 7: TGA curves of a pure PANI-ES obtained in nitrogen atmosphere at heating rate of $10^{\circ} \mathrm{C} / \mathrm{min}$.

Figure 8 is the DSC thermogram of the PANI-EB form powder in the first run and second run. In the first run there were two endothermic peaks at 55.99 and $103.46^{\circ} \mathrm{C}$ and the PANI-EB powder had discernible moisture content [16]. Therefore, these endothermic peaks were most likely due to the evaporation of water. This was in agreement with the TGA results.
In the second run, there were almost no significant endothermic or exothermic peaks, as shown in Figure 8, because no apparent moisture existed in the sample but $\mathrm{Tg}$ appear at $74.06^{\circ} \mathrm{C}$.

First run and second run in Figures 9 and 10 show the DSC cooling trace of the PANI-ES and PANI-HCl. Two remarks can be observed. (a) Three endothermic peaks; these 
TABLE 2: Thermodynamics properties of different forms of polyaniline $T\left({ }^{\circ} \mathrm{C}\right), \Delta H(J / g), \Delta C p\left(J / g *{ }^{\circ} \mathrm{C}\right)$.

\begin{tabular}{lcccccccc}
\hline Sample & $T_{1}$ & $T_{2}$ & $T_{3}$ & $T g$ & $\Delta H_{1}$ & $\Delta H_{2}$ & $\Delta H_{3}$ & $\Delta C p$ \\
\hline PANI-EB & 55.99 & 103.46 & $\mathrm{X}$ & 74.06 & 4.3161 & 20.5363 & $\mathrm{X}$ & 0.311 \\
PANI-ES & 50.34 & 140.10 & 221.07 & 103.75 & 167.6042 & 4.4617 & 10.7719 & 0.154 \\
PANI-HCL & 100.45 & 163.09 & 218.57 & 126.89 & 1.9678 & 8.7614 & 16.8337 & 0.180 \\
\hline
\end{tabular}

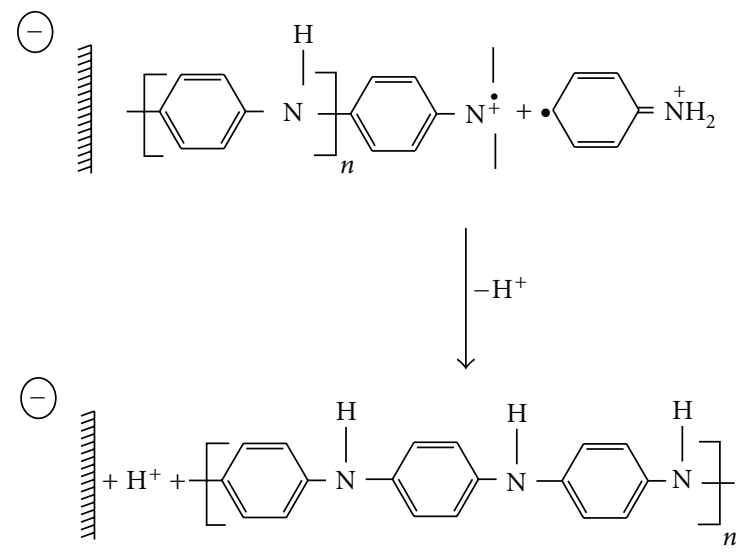

SCHEME 4

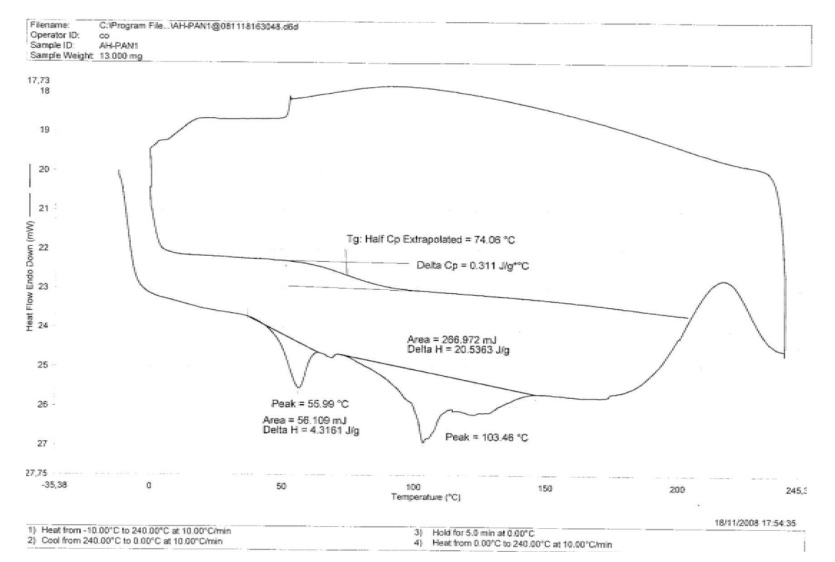

FIGURE 8: Typical DSC thermogram on annealed polyaniline (PANI-EB) obtained in the glass transition region at a heating rate of $10^{\circ} \mathrm{C} / \mathrm{min}$.

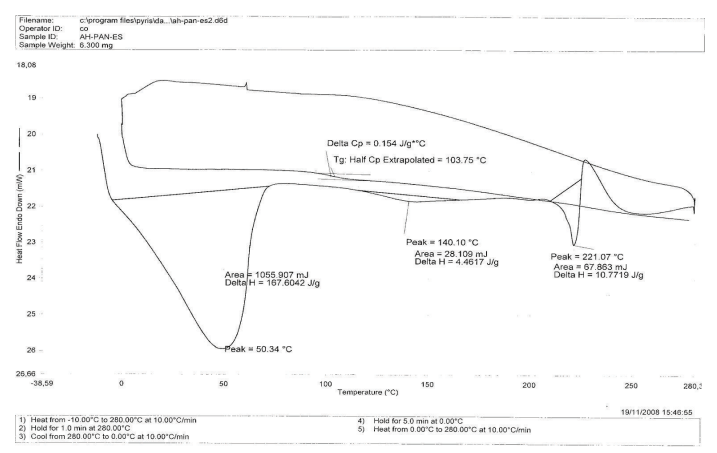

FIgURE 9: DSC curve of the PANI-ES composite obtained in nitrogen atmosphere at heating rate of $10^{\circ} \mathrm{C} / \mathrm{min}$.

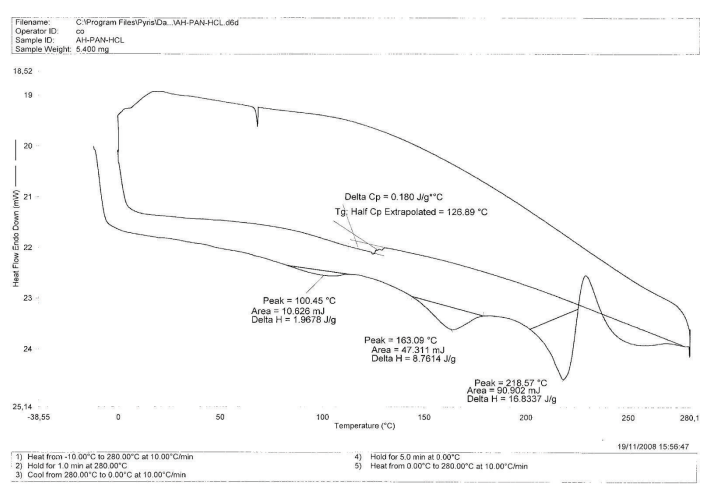

FIGURE 10: DSC Curve of the PANI-HCl composite obtained in nitrogen atmosphere at heating rate of $10^{\circ} \mathrm{C} / \mathrm{min}$.

peaks were most likely due to the evaporation of water, evaporation of dopant, and degradation of the polymer, respectively. (b) Higher glass transition temperatures $(\mathrm{Tg})$ than their counterpart PANI-EB; the $T g$ of the polymer increases slightly with the increasing of the conductivity. For example, the $\mathrm{Tg}$ of PANI-EB is around $74.03^{\circ} \mathrm{C}$, whereas the $\mathrm{Tg}$ is shifted to around $103.75^{\circ} \mathrm{C}$ for PANI-ES and $126.89^{\circ} \mathrm{C}$ for PANI-HCL. These observations are well in agreement with the results reported by other research [17]. For more information such as stability, conductivity, solubility, chemical structure, and morphology of different form of polyaniline, Table 2 shows the thermodynamics properties of different states of polyaniline.

3.4. Proposed Mechanism of the Reaction. The proposed mechanism of cationic polymerization of (PANI) catalyzed by Maghnite- $\mathrm{H}^{+}$. 
(1) Initiation (see Scheme 2). The mechanism of the reaction occurs within the layers of the Maghnite exchanged by $\mathrm{H}^{+}$ protons, which are capable of initiating cationic polymerization in the presence of the oxidant $\mathrm{K}_{2} \mathrm{~S}_{2} \mathrm{O}_{8}$.

(2) Propagation (see Scheme 3). Propagation is by the successive addition of monomers on the chain macromere growing.

(3) Termination (see Scheme 4). The termination takes place during the recombination of two radical ions giving rise to the final polymer.

\section{Conclusion}

Polyaniline has been intensively studied recently due to its various properties as well as to its environmental stability. The thermal behavior of polyaniline PANI-ES, PANI-EB, and PANI-HCl were studied using thermogravimetric analysis and differential scanning calorimetry. The montmorillonite clay has received intensive attention because it is natural, abundant, cheap, and has high chemical resistance. Therefore, the aim of this paper is to improve the thermal stability of PANI through the synthesis with layered materials. Although the polymer is black, which could be identified as PANI-ES.

It has been proved that $\mathrm{Mag}-\mathrm{H}^{+}$can be used to induce the polymerization of aniline, and this offers new possibilities for the selective study of montmorillonite as catalysts and for the synthesis of polymers conductors such as polypyrrole, polythiophene, polyaniline, and there derivates.

\section{References}

[1] Y. Cao, P. Smith, and A. J. Heeger, "Spectroscopic studies of polyaniline in solution and in spin-cast films," Synthetic Metals, vol. 32, no. 3, pp. 263-281, 1989.

[2] N. Kuramoto and E. M. Geniès, "Micellar chemical polymerization of aniline," Synthetic Metals, vol. 68, no. 2, pp. 191-194, 1995.

[3] S. L. Wang and C. M. Chen, Undergraduate Research Report, Chemical Engineering department, Southern Taiwan University of Technology, 2000.

[4] S. SinhaRay and M. Biswas, "Preparation and evaluation of composites from montmorillonite and some heterocyclic polymers: 3. A water dispersible nanocomposite from pyrrolemontmorillonite polymerization system," Materials Research Bulletin, vol. 34, no. 8, pp. 1187-1194, 1999.

[5] M. Belbachir and A. Bensaoula, "Composition and Method for Catalysis using Bentonites," United States Patent Number: 6274527 B1, 2001.

[6] K. S. Ryu, K. M. Kim, S. G. Kang, G. J. Lee, J. Joo, and S. Chang, "Electrochemical and physical characterization of lithium ionic salt doped polyaniline as a polymer electrode of lithium secondary battery," Synthetic Metals, vol. 110, no. 3, pp. 213 $217,2000$.

[7] M. Belbachir and A. Bensaoula, "Composition and Method for Catalysis using Bentonites," United States Patent Number: 2003/0069446 A1, 2003.
[8] W. Zheng, M. Angelopoulos, A. J. Epstein, and A. G. MacDiarmaid, "Experimental evidence for hydrogen bonding in polyaniline: mechanism of aggregate formation and dependency on oxidation state," Macromolecules, vol. 30, no. 10, pp. 2953-2955, 1997.

[9] B. Wessling and H. Volk, "Thermoplastic conversion of "doped" polyaniline from the amorphous to a partially crystalline state," Synthetic Metals, vol. 16, no. 1, pp. 127-131, 1986.

[10] A. Yahiaoui and M. Belbachir, "Ring-opening polymerization of styrene oxide with maghnite- $\mathrm{H}^{+}$as ecocatalyst," Journal of Applied Polymer Science, vol. 100, no. 2, pp. 1681-1687, 2006.

[11] H. J. Choi, J. W. Kim, J. Joo, and B. H. Kim, "Synthesis and electrorheology of emulsion intercalated PANI-clay nanocomposite," Synthetic Metals, vol. 121, no. 1-3, pp. 1325-1326, 2001.

[12] M. Alexandre and P. Dubois, "Polymer-layered silicate nanocomposites: preparation, properties and uses of a new class of materials," Materials Science and Engineering R, vol. 28, no. 1, pp. 1-63, 2000.

[13] G. M. Nascimento, V. R. L. Constantino, R. Landers, and M. L. A. Temperini, "Aniline polymerization into montmorillonite clay: a spectroscopic investigation of the intercalated conducting polymer," Macromolecules, vol. 37, no. 25, pp. 9373-9385, 2004.

[14] Y. Wei, K. F. Hsueh, and G. W. Jang, "Monitoring the chemical polymerization of aniline by open-circuit-potential measurements," Polymer, vol. 35, no. 16, pp. 3572-3575, 1994.

[15] J. Yue, A. J. Epstein, Z. Zhong, P. K. Gallagher, and A. G. Macdiarmid, "Thermal stabilities of polyanilines," Synthetic Metals, vol. 41-43, pp. 765-768, 1991.

[16] Y. Wei, G. W. Jang, K. F. Hsueh, E. M. Scherr, A. G. MacDiarmid, and A. J. Epstein, "Thermal transitions and mechanical properties of films of chemically prepared polyaniline," Polymer, vol. 33, no. 2, pp. 314-322, 1992.

[17] X. Y. Shang, Z. K. Zhu, J. Yin, and X. D. Ma, "Compatibility of soluble polyimide/silica hybrids induced by a coupling agent," Chemistry of Materials, vol. 14, no. 1, pp. 71-77, 2002. 

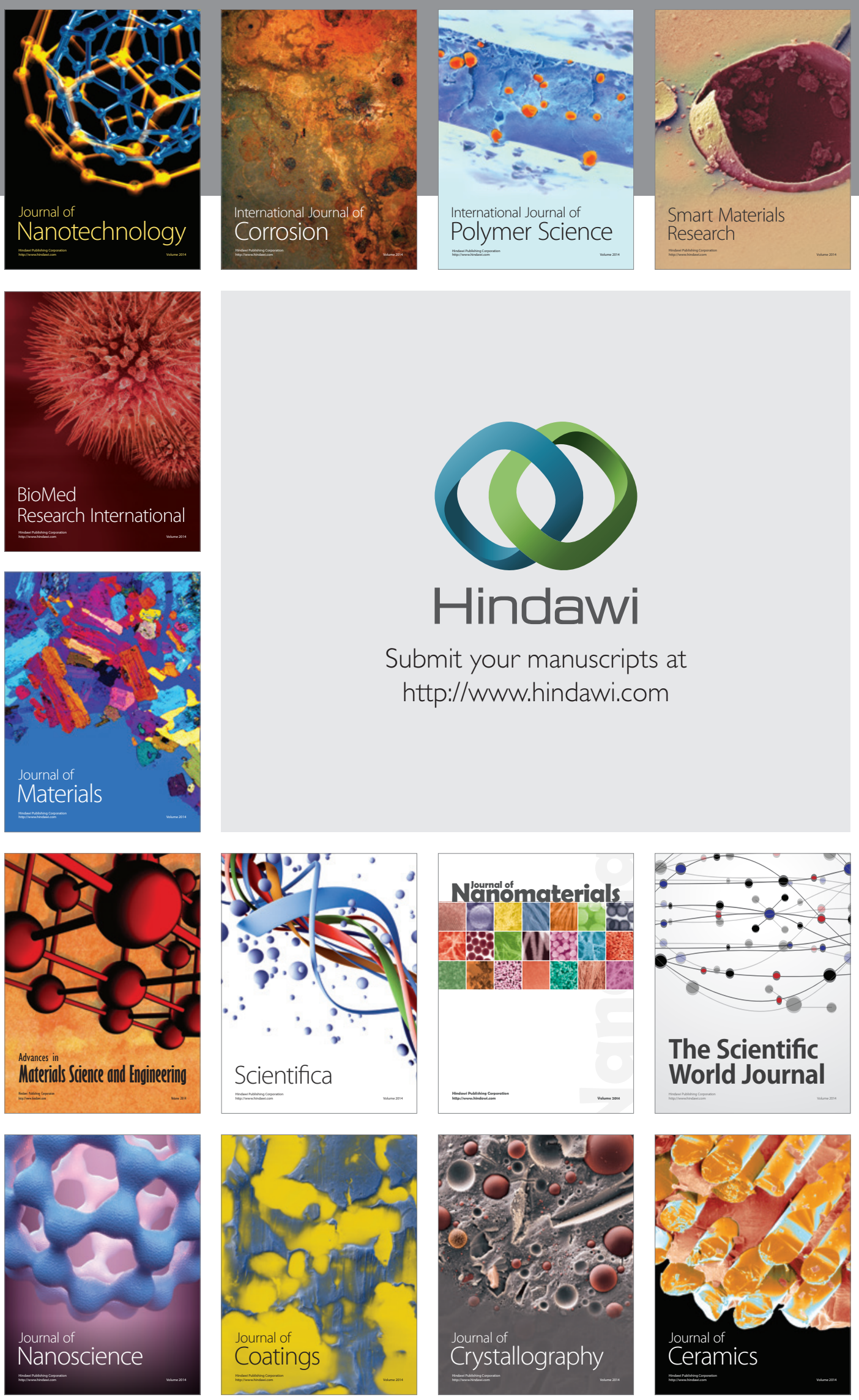

The Scientific World Journal

Submit your manuscripts at

http://www.hindawi.com

\section{World Journal}

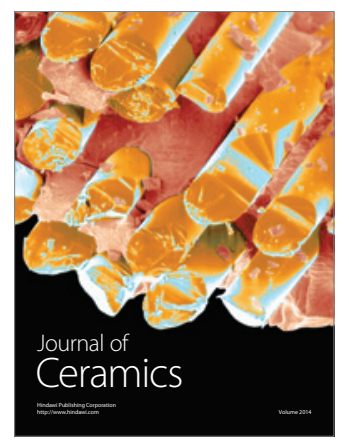

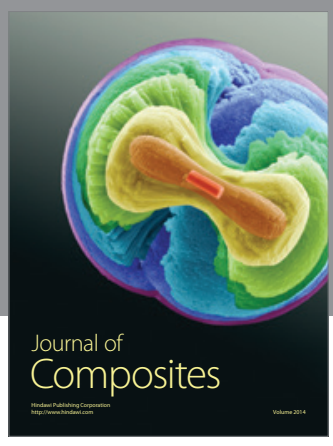
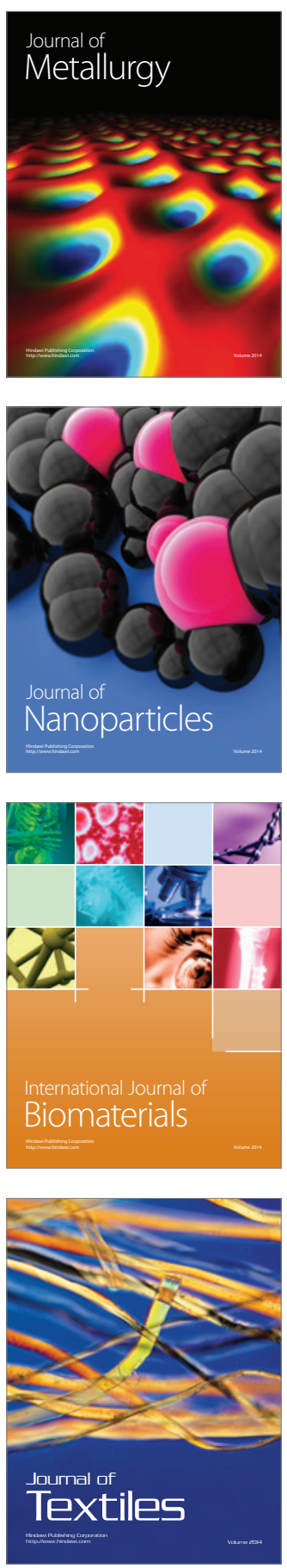